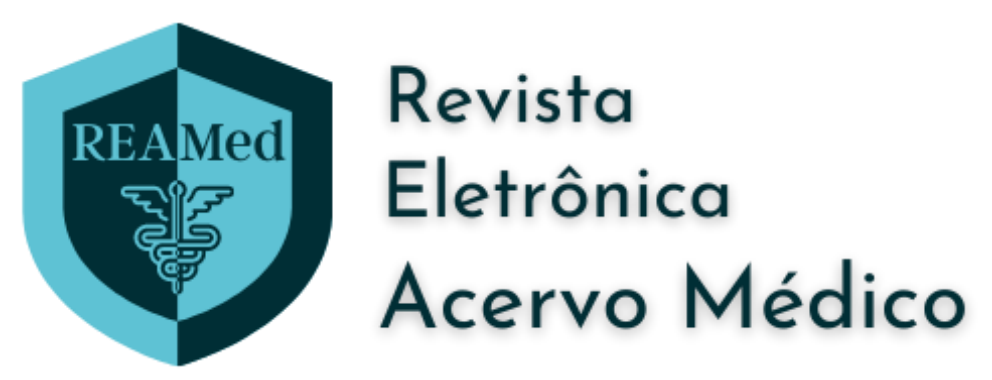

\title{
Doenças inflamatórias intestinais: uma abordagem geral
}

\author{
Inflammatory bowel diseases: a general approach
}

\author{
Enfermedades inflamatorias del intestino: abordaje general
}

Lanna do Carmo Carvalho ${ }^{1 *}$, Esaú Simões da Silva², Anna Lidía Masson Roma1, José Eduardo Godoy Lauriano ${ }^{1}$, Sâmella Cotrim dos Reis ${ }^{1}$, Fernando Valdino Silva Costa ${ }^{1}$, Ricardo Olavo de Carvalho Bezerra ${ }^{3}$, Mylena Francyele Queiroz Rocha ${ }^{4}$, Valmir Queiroz Mariano Filho ${ }^{3}$, Lara Cândida de Sousa Machado'.

\section{RESUMO}

Objetivo: Descrever e abordar sobre as considerações gerais e pontos mais importantes das doenças inflamatórias intestinais. Revisão bibliográfica: As doenças inflamatórias intestinais abordam uma variedade de condições, mas o foco textual e o contexto clinico se voltam para a doença de Crohn e a retocolite ulcerativa, em função de seu caráter idiopático e autoimune, e também por apresentar um quadro clínico exuberante, fisiopatologia abrangente, semelhanças entre si e demais desordens intestinais inflamatórias e em algumas situações não se limitam só ao acometimento da porção digestiva e desencadeiam acometimentos extra-intestinais e impactam negativamente a saúde e a qualidade de vida do paciente por sintomatologias oriundas do quadro de base ou terapêutica. Considerações finais: As doenças inflamatórias intestinais possuem elevada importância clínica e mesmo com a falta de comprovações sobre o fator desencadeante e outros aspectos relevantes é possível conhecer o quadro clínico, realizar o diagnóstico diferencial e seguir uma conduta terapêutica adequada.

Palavras-chave: Inflamação, Doença, Autoimune.

\section{ABSTRACT}

Objective: Describe and address the general considerations and most important points of inflammatory bowel diseases. Bibliographic review: Inflammatory bowel diseases address a variety of conditions, but the textual focus and clinical context turn to Crohn's disease and ulcerative colitis, due to its idiopathic and autoimmune character, and also for presenting an exuberant clinical picture, comprehensive pathophysiology, similarities between them and other inflammatory bowel disorders and in some situations are not limited to the involvement

\footnotetext{
1 Universidade de Rio Verde (UNIRV), Rio Verde - GO. *E-mail: lannacarmo@outlook.com

2 Centro Universitário São Miguel (UNISÃOMIGUEL), Recife - PE.

${ }^{3}$ Faculdade de Medicina Nova Esperança (FAMENE), João Pessoa - PB.

${ }^{4}$ Centro Universitário CESMAC, Maceió - AL.
}

SUBMETIDO EM: 1/2022 
of the digestive portion and trigger extra-intestinal affections and negatively impact the health and quality of life of the patient due to symptoms arising from the baseline condition or therapy. Final considerations: Inflammatory bowel diseases have high clinical importance and even with the lack of evidence on the triggering factor and other relevant aspects, it is possible to know the clinical picture, perform the differential diagnosis and follow an appropriate therapeutic approach.

Key words: Inflammation, Disease, Autoimmune.

\section{RESUMEN}

Objetivo: Describir y abordar las consideraciones generales y los puntos más importantes de las enfermedades inflamatorias intestinales. Reseña bibliográfica: Las enfermedades inflamatorias intestinales abordan una variedad de condiciones, pero el enfoque textual y el contexto clínico giran hacia la enfermedad de Crohn y la colitis ulcerosa, por su carácter idiopático y autoinmune, y también por presentar un cuadro clínico exuberante, fisiopatología integral, similitudes entre ellos y otros trastornos inflamatorios intestinales y en algunas situaciones no se limitan al compromiso de la porción digestiva y desencadenan afecciones extraintestinales e impactan negativamente en la salud y calidad de vida del paciente debido a los síntomas derivados de la condición de base o de la terapia. Consideraciones finales: Las enfermedades inflamatorias intestinales tienen una alta importancia clínica y aún con la falta de evidencia sobre el factor desencadenante y otros aspectos relevantes, es posible conocer el cuadro clínico, realizar el diagnóstico diferencial y seguir un abordaje terapéutico adecuado.

Palavras clave: Inflamación, Enfermedad, Autoinmune.

\section{INTRODUÇÃO}

A Doença Inflamatória Intestinal (DII) é um conceito comum, para mencionar algum processo inflamatónio localizado na porção do trato digestivo, podendo ser agudo ou crônico. Geralmente, infecções por bactéria, vírus, protozoário, isquemia, radiação e também a forma idiopática, a qual a Retocolite Ulcerativa (RCU) e a Doença de Crohn (DC) são as principais representantes (CAVALCANTE RMS, et al., 2020).

A RCU é uma patologia contínua, se dissemina retrógrada e simetricamente, com início na junção anorretal para segmentos cólicos proximais, numa maior ou menor extensão. Em contraste, a DC cursa com acometimento segmentar, assimétrico e focal. $O$ reto normalmente é poupado na $D C$, ao passo que o íleo terminal está em 85\% dos pacientes com a afecção (PROTASIO BKPF, et al., 2018).

Ambas devem ser distinguidas das demais que também promovem inflamação intestinal, como infecções, diverticulite, apendicite, enterite por radiação, fármacos e vasculite intestinal. A DC e a RCU são crônicas de causa não conhecida que têm o mesmo perfil epidemiológico, clínico e terapêutico, mas dispõem de importantes diferenças (TORRES J, et al., 2017).

O fator de risco determinante para ambas é a genética, comprovada pela incidência em torno de 10-25\% dos pacientes. A importância genética é corroborada pelo fato de síndromes como Turner e Wiskott-Aldrich se associarem a uma incidência elevada das DII. Em acometidos, os parentes de primeiro grau são muito suscetíveis do que a população geral (SILVA FARS, et al., 2020).

Atualmente, há o predomínio da RCU em homens, ao passo que na DC haveria uma taxa superior em mulheres. A questão do gradiente norte-sul, a observação de que as DIl são mais habituais quanto mais para o norte nos mudarmos, com maior incidência na América do Norte e Europa, em relação ao continente latinoamericano, África e Ásia. Ademais, as DIl são mais comuns em brancos, especialmente Judeus. Existem dois picos de incidência: o principal entre 15-40 anos e 50-80 anos (FERREIRA GS, et al., 2020).

Partindo desse contexto, o seguinte estudo objetivou descrever sobre as considerações gerais e pontos mais importantes das doenças inflamatórias intestinais. 


\section{REVISÃo BIBLIOGRÁFICA}

A narrativa fundamentada na literatura buscou descrever as principais generalidades das DII, com foco na DC e RCU de forma coesa e sucinta. Por conseguinte, para melhor organização e compreensão, o artigo foi subdividido em categorias.

\section{Fisiopatologia}

A RCU e DC são idiopáticas e autoimunes, evidenciado que não há um desencadeante específico e com o seu desenvolvimento o organismo não está apto a regular a reação imune para combater os antígenos aos quais a porção digestiva está exposta (FERREIRA GS, et al., 2021). Apesar do caráter idiopático, a interação de fatores genéticos, luminais, imunes e ambientais são muito investigadas e estão presentes significativamente nos acometidos (LIMA CCG, et al., 2020).

Os fatores genéticos apontam mais de 163 genes detectados na RCU e DC. Pessoas com algum parente acometido têm probabilidade mais elevada de desenvolver o quadro. Ressaltando, o gene NOD2/ CARD15 é muito relacionado a susceptibilidade a desenvolver à doença de Chron (PROTASIO BKPF, et al., 2018).

A microbiota intestinal não é considerada um fator ou ef eito da inflamação, mas os portadores têm redução na colonização de microrganismos, propiciando alterações abruptas de fatores externos (DIAS PAR, et al., 2020).

As DII cursam com desequilíbrio negativo da reação imune intestinal inata e adaptativa, com agressão epitelial por síntese excessiva de muco, infiltrações linfociticas e células dendríticas na lâmina própria (CAVALCANTE RMS, et al., 2020).

Os fatores externos como uso de anticonceptivo oral, excesso de antibióticos nos primeiros anos de vida, exposição vacinal e estresse podem exacerbar a inflamação intestinal. Exercem influência positiva 0 aleitamento materno e a apendicectomia (FERREIRA IF, et al., 2020).

O tabagismo é considerado pelo Ministério da Saúde um hábito de agravo a saúde, confirmado pela intensificação e agravo na DC. Mas, mesmo sem a devida evidência, é um fator de proteção para a RU. Além desses fatores, uma dieta rica em industrializados, ultra refinados e contaminados são potenciais para danificar a saúde intestinal e exacerbar episódios inflamatórios (DIAS PAR, et al., 2020).

\section{Quadro clínico}

A DC acomete as camadas intestinais de forma transmural, podendo se manifestar da boca ao ânus. As porções alvo são o íleo e cólon, seguindo um percurso aleatório de dano endotelial e o quadro clínico se assemelha a ileocolite (DIAS PAR, et al., 2020).

O desencadeamento da síndrome disabsortiva, resulta em desnutrição, diarréia crônica com dor abdominal e demais acometimentos devido ao abalo absortivo do intestino delgado. Úlceras aftóides, profundas, confluentes, lesões em salto no intestino, distribuição segmentar com aspecto assimétrico e em pedra de calçamento junto aos pseudo pólipos inflamatórios surgem na fase precoce. Na tardia, é comum fissuras, fistulas, perda das haustrações, estenoses fibróticas e abscessos intramurais (NASCIMENTO APS, et al., 2020). No exame físico, durante a palpação no quadrante inferior direito a detecção de massa saliente induz a suspeição de alça intestinal com edema, DC e abscesso intra-abdominal. (FERREIRA GS, et al., 2021).

A RC é limitada a mucosa intestinal, af eta em específico o intestino grosso e reto. Caracteriza-se por lesões contínuas e ascendente, sendo a migração do tecido patológico para o saudável nítido e circunscrito. A sintomatologia cursa com diarréia sanguinolenta que muda de proporção e período interpostos por ausência, febre e raras vezes dor abdominal. O início é indolente, sem alardes e a detecção é feita pós nove meses, a qual têm se eventos de redução da complacência do reto inflamado, aumento da necessidade de defecar e tenesmo. A hematoquezia é um sinal habitual da condição, em razão de af etar a mucosa colônica e resultar em friabilidade dessa porção, a qual diante a inexistência de sangue ser princípio para exclusão diagnóstica. Raro, a doença iniciar com diarréia agressiva, repentina, toxemia e síndrome febril. O processo quando contido no retossigmoide, os dejetos se encontram normais ou rígidos, com chance de retenção de 
fezes, em consequência da inflamação estar restrita ao lado esquerdo do cólon e estancar a peristalse do cólon direito (BRITO RCV, et al., 2020).

Anormalidades laboratoriais como anemia por falta de ferro oriunda de hemorragia. Em quadros extensos de colite a perda protéica pela exsudação da inflamação colônica. Simultaneamente, a menor produção hepática de albumina, vista nas inflamações sistêmicas, esta última pode justificar uma hipoalbuminemia. Em casos graves de inflamação sistêmica, é comum surgir a leucocitose com desvio. As manifestações extraintestinais da RCU são mais frequentes nas formas extensas além da flexura esplênica (COTRIM MA, et al., 2020).

\section{Manifestações extraintestinais}

As manifestações extraintestinais são comuns, com prevalência em torno de $20,1 \%$ na DC e $10,4 \%$ na RCU é alto indicativo de doença ativa. As manifestações gastrointestinais variam de acordo com a porção injuriada e o nível de extensão e podem af etar diversas estruturas, como articulações, pele, olhos, via biliar, sistema nervoso central, coração, pulmões, rins. As manifestações extraintestinais podem ser classificadas em imunomediadas ou não, relacionadas a alterações metabólicas ou processos secundários (TORRES J, et al., 2017). Algumas são de curto prazo e se associam à ativação da doença como artrite periférica, eritema nodoso, af tas orais e episclerite outras seguem um curso independente como o pioderma gangrenoso, uveíte, artropatia axial e colangite esclerosante primária (FERREIRA IF, et al., 2020).

O acometimento articular costuma ser assimétrico, migratório e não erosivo. A artropatia periférica tipo I têm relação com a doença intestinal acometendo grandes articulações, ser aguda, assimétrica e autolimitada. A artropatia periférica tipo Il é crônica e cursa com poliartrite de pequenas articulações, em especial das mãos independente da ação da doença. A artropatia axial inclui a sacroileíte e a espondilite anquilosante; sem relação direta com ação intestinal (SOUZA FG, et al., 2021).

A agressão cutânea aborda o eritema nodoso em cerca de 4\% das vezes, nódulos subcutâneos dolorosos, com diâmetro variado, localizados principalmente em superfícies extensoras das extremidades e face tibial anterior. É comum estar relacionada á atividade de doença. O pioderma gangrenoso ( $0,75 \%$ dos pacientes) é uma lesão junto ao trauma local, localizada sobretudo na região pré-tibial ou próxima a estomas. Inicialmente marcada por pústula eritematosa, única ou múltiplas, que coalescem para formar uma úlcera profunda com fundo necrótico e estéril (FERREIRA IF, et al., 2020).

$\mathrm{O}$ ataque ocular, é comum ocorrer episclerite e esclerite. A uveíte é uma manifestação caracterizada por algia ocular, fotofobia, hiperemia ocular e lacrimejamento. Quando não adequadamente tratada pode causar perda irreversível da visão. A nictalopia, é consequência da má absorção de vitamina A. Casos de catarata precoce são muito relacionados ao uso de corticosteroides (CAVALCANTE RMS, et al., 2020).

O dano renal eleva os riscos de formação de cálculo, oriundo da má absorção intestinal. O acometimento hematológico pode resultar em trombose venosa profunda e tromboembolismo pulmonar. Outras manif estações incluem o risco relativo para colelitíase, em razão da redução do total de sais biliares por menor absorção ileal, ef eito da doença, ressecção sequente saturação biliar de colesterol e limitação da motilidade da vesícula biliar. No geral, é comum a dor abdominal, êmese, enjoo, caquexia, anorexia, febre e lipotímia (ZALTMAN C, et al., 2019).

\section{Critérios diagnósticos}

A junção simultânea da história clínica, endoscopia, anatomopatologia e marcadores sorológicos são a base para alcançar o diagnóstico acurado. Na RU a retossigmoidoscopia com biópsia é o exame de escolha. A maioria têm lesão inflamatória do reto, a proctite e do cólon sigmoide, a proctossigmoidite. É visto um comprometimento uniforme e contínuo, manifesto por extinção vascular na mucosa, úlceras, exsudação e em casos crônicos, os pseudopólipos. Suspeições em agravos, defecações diárias e sinais sistêmicos a colonoscopia com biópsia é a mais apropriada, mas não indicada mediante megacólon tóxico. Alterações e abscessos nas criptas, neutrofilia epitelial e depósito linfoplasmocitário na lâmina própria são os achados histológicos mais comuns (SILVA MT, et al., 2020). 
A análise anatomopatológica da RU, exibe variações no nível de implicação. Cerca de 50\% dos casos, a doença é circunscrita à mucosa retal não mais que $15 \mathrm{~cm}$ da linha denteada, categorizando a proctite, até 30 $\mathrm{cm}$ da linha denteada, personalizando a proctossigmoidite. Por volta de $40 \%$ dos doentes, a extensão se alastra até a flexura esplênica, tipificando a colite esquerda (COTRIM MA, et al., 2020).

Entre $30 \%$ destes a inflamação ultrapassa a flexura esplênica, identificando a colite extensa. Diante lesões da flexura hepática, a inflamação que ultrapassa o cólon transverso é denominada pancolite. Raro afetar o intestino delgado distal por exsudação, a ileíte de refluxo, é parâmetro de agravo da colite, devido a RC não danificar o íleo, mas ocorre pela comunicação entre o conteúdo colônico tóxico ao íleo distal (SU HJ, et al., 2019).

A análise macroscópica da mucosa colônica varia do normal até a total desnudação. Pode haver perda do molde vascular próprio do cólon, hiperemia, edema, mucosa friável, erosões, ulcerações, destilação de muco e sangue. Os pseudopólipos, surgem em $30 \%$ dos casos. A cronicidade exibe mucosa pálida e atrófica. As alterações da RCU se dão de modo uniforme e contínuo (PROTASIO BKPF, et al., 2018).

Em RCU grave, mudanças af etam, a submucosa e a muscular, por contiguidade e não por via direta da doença. Eventos que predispõe fragilidade na parede intestinal e risco de megacólon tóxico e perfuração. Na $\mathrm{RC}$ desenvolvida, são comuns alterações da musculatura colônica, que, ao exame radiológico, apresentam perda das haustrações e espessamento da musculatura lisa com aspecto de "cano de chumbo". A terapêutica, predispõe o retorno de início na extremidade proximal ao intestino delgado, sendo o reto o segmento final a melhorar. Mesmo com o controle, continua o desvio do padrão mucoso vascular, e a formação de pseudopólipos pós-inflamatórios com projeções filamentosas, semelhantes aos adenomatosos. Longos períodos de RC, pode formar displasia epitelial, relacionada com formação neoplásica colônica maligna e complicação tardia de DC (CAVALCANTE RMS, et al., 2020).

A maioria dos portadores de DC têm o íleo terminal, cólon ascendente e ceco af etado. A ileonoscopia com biópsias é o primeiro exame. As sondas de colonoscopia penetram no íleo terminal puncionando biópsias. Nota-se áreas doentes alternadas com áreas sãs, manifesto por úlceras aftosas que, quando coalescentes, dão o aspecto de "pedras de calçamento". O histopatológico lembra achados da RC, mas os granulomas não caseosos, são patognomônicos de Crohn (MARANHÃO DDA, et al., 2015).

Os meios de diagnóstico por imagem são muito úteis, pois informam de modo não invasivo a extensão do acometimento digestivo, detectam complicações como obstrução intestinal e fístulas internas. Os exames de imagem mais requisitados antigamente eram o clister opaco e o trânsito de delgado. O clister opaco contrastado com ar, o conhecido contraste duplo pode indicar na RC perda de haustros, granularidade difusa em áreas contíguas, ulcerações superficiais, pseudopólipos e cólon em aspecto tubular (TORRES J, et al., 2017).

Na DC é comum ulcerações assimétricas, focais, fístulas, resguardo retal e íleo terminal comprometido. A enteróclise, o exame contrastado usual para estimar o trânsito de delgado era classicamente eficaz para indicar a extensão do acometimento do delgado pela DC, mas não possui valor na RCU sem ileíte de refluxo (ZALTMAN C, et al., 2019).

Há meios mais acurados como a entero-TC ou a entero-RNM. Tais vias detectam áreas intestinais alteradas, em função de demonstrar espessura elevada, hipercaptação focal de contraste, sendo obtidos de forma mais precoce em comparação ao trânsito de delgado e a visualização de todo o tubo digestivo (FERREIRA IF, et al., 2020).

As sorologias são a positividade do ASCA com especificidade em torno de $97 \%$ e $49 \%$ sensibilidade para a DC. A positivação do p-ANCA é específico cerca de $97 \%$ e sensível em $57 \%$ para RU. Ademais, a presença de Anti-OmpC e anti-CBir1 são muito sugestivos de DC (SILVA FARS, et al., 2020).

\section{Diagnóstico diferencial}

O diagnóstico diferencial aborda outras patologias que prejudicam o trato digestivo de forma funcional ou orgânica. Dentre as doenças funcionais intestinais, a síndrome do intestino irritável é a que mais se 
assemelha, apesar de caracteristicamente se diferencie da RC e DC por não cursar com febre, perda de peso, hemorragia ou manifestações extraintestinais (BARROS GVN, et al., 2020).

Outras devem ser descartadas, como colite secundária ao uso de medicações com foco nos antiinflamatórios não esteroidais, doença isquêmica, colite actínica secundária à radiação, colite microscópica, colite neutropênica, colagenoses, tuberculose e linfoma intestinal (FERREIRA IF, et al., 2020).

Os portadores da síndrome do cólon irritável se apresentam inflamados. O clister opaco e a sigmoidoscopia não exigem alterações. A persistência sintomatológica junto ao tratamento específico, sobretudo com perda de peso, sangramento retal, muitas vezes atribuído às hemorroidas e história familiar indicam investigação mais aprofundada (SILVA MT, et al., 2020).

A gastroenterite viral dura pouco, não são inflamatórias. A maioria das infecções entéricas bacterianas é autolimitada, com tempo curto e a minoria é inflamatória. Mas, eventos como infecção bacteriana pode resultar em diarreia inflamatória com sangue, muco, pus e mucosa de aspecto endoscópico indistinguível das DIl. Os exemplos típicos são: Salmonella Shigella, Campylobacter jejuni, Clostridium difficile, Yersinia enterocolítica. A amebíase pode cursar com diarreia, hemorragia retal e aspecto endoscópico semelhante ao das DII, o que faz da investigação de cistos, trofozoítos ou antígenos de ameba em fezes frescas fundamental A tuberculose entérica, resulta de modo personalizado em estenoses no íleo terminal, ceco e cólon ascendente. $O$ bacilo de Koch gera inflamação granulomatoso pode ser indiferenciavel histologicamente da DC, urgindo por colorações e culturas (CAVALCANTE RMS, et al., 2020).

Achados persistentes de hemorragia retal não deve ser relacionado a hemorroidas, exceto pela exclusão por sigmoidoscopia. O câncer de cólon também pode suceder com sintomas crônicos e sangramento retal intermitente. O linfoma intestinal pode ser difícil diferenciar da DC, exigindo diagnóstico cirúrgico (BRITO RCV, et al., 2020).

A colite colágena ocorre mais em mulheres de meia-idade, caracterizada diarreia aquosa crônica. A colonoscopia pode ser normal ou revelar inflamação leve. O diagnóstico é por biópsia, que mostra depósitos espessos de colágeno abaixo do epitélio (BARROS GVN, et al., 2020).

\section{Tratamento}

As DIl têm caráter crônico e ainda não têm cura, mas é possível controlar as exacerbações sintomatológicas por fármacos derivados da mesalazina, glicocorticoides, imunomoduladores e agentes biológicos (SOUZA FG, et al., 2021).

O ácido 5-aminosalicílico (mesalazina) atua como anti-inflamatório tópico na mucosa intestinal. São eficazes na indução da remissão e manutenção da remissão. Os meios anti-inflamatórios vistos são a redução da cascata do ácido araquidônico relacionado as vias da cicloxigenase, lipoxigenase e do fator ativador de plaquetas e inibição da síntese de radicais livres, da função linfomonocitária, imunoglobulinas e interleucinas do tipo um (PILEGGI GS, et al., 2019).

Os glicocorticoides são administrados só para indução da remissão e não na manutenção nas DII moderadas a graves, visando a rápida melhora da inflamação. Os corticosteroides são usados principalmente para tratar as exacerbações de RC e DC. As formulações orais são usadas para a doença leve a moderada, enquanto os sistêmicos para doença moderada a grave. Por via oral, a clássica prednisona é eficaz, atualmente sendo substituída pela budesonida, devido ao menor ef eito sistêmico que os demais e leve ou nenhuma inibição do eixo hipotalâmico-hipofisário-adrenal. A via endovenosa é restrita a inflamação intestinal intensa, a ponto de inviabilizar a via oral e diante sintomatologia de inflamação sistêmica exuberante. As drogas usuais são a hidrocortisona e a metilprednisolona (SILVA MT, et al., 2020).

Os imunomoduladores principais são as tiopurinas: azatioprina e mercaptopurina. São úteis em quadros moderado a grave (DC ou RCU) associados a um agente anti-TNF ou em acometidos inaptos em reduzir a dose de glicocorticoide sem exacerbação. Tais drogas são potentes imunossupressores, inibindo a ação linfocitária e células natural killer. O metotrexate é o imunomodulador de segunda linha, sendo reservado aos intolerantes as tiopurinas (SU HJ, et al., 2019). 
Os agentes biológicos são anticorpos monoclonais quiméricos ou humanizados que têm como alvo moléculas essenciais para a cascata inflamatória. Existem duas classes em uso clínico: os agentes anti-TNF e os agentes anti-integrina. São essenciais na terapia das DIl específicas como em DC fistulizante, CU aguda grave e em sintomatologias extra-intestinais (LIMA CCG, et al., 2020).

\section{CONSIDERAÇÕES FINAIS}

As DII, sendo autoimunes, não tem cura. Mas, existem tratamentos para que a doença seja controlada e a pessoa não tenha sua qualidade de vida prejudicada. Existe a associação da manifestação clinica com a genética e fatores externos, a qual influenciam no desencadeamento das principais DII, a DC e a RCU, a qual cursam com sintomatologias semelhantes, mas que são condições impostas e precisam ser diagnosticadas e tratadas de modo precoce.

\section{REFERÊNCIAS}

1. BARROS GVN, et al. Métodos diagnósticos e terapêuticos das doenças inflamatórias intestinais: revisão sistemática. Pará Research Medical Journal, 2020; 4(42):e42.

2. BRITO RCV, et al. Doenças inflamatórias intestinais no Brasil: perfil das internações, entre os anos de 2009 a 2019. Revista Educação em Saúde, 2020;8(1).

3. CAVALCANTE RMS, et al. Retocolite ulcerativa e citocinas: uma revisão de literatura. Research, Society and Development, 2020;9(9), e314997145.

4. COTRIM MA, et al. O papel da microbiota intestinal na patogênese das doenças inflamatórias intestinais. Brazilian Journal of Health Review, 2020; 3(3).

5. DIAS PAR, et al. A relação do microbioma intestinal e o sistema imune no desenvolvimento da doença de Chron. Revista Eletrônica Acervo Científico, 2020;17, e5618.

6. FERREIRA IF, et al. Manifestações cutâneas na doença de Chron: diagnóstico e prognóstico. Revista Eletrônica Acervo Científico, 2020; 13, e4690.

7. FERREIRA GS, et al. Fisiopatologia e etiologias das doenças inflamatórias intestinais: uma revisão sistemática de literatura. Brazilian Journal of Health Review, 2021;4(4).

8. LIMA CCG, et al. Análise crítica do uso dos anti-TNF na era dos novos agentes biológicos na doença inflamatória intestinal, 2020;57(3): 323-332.

9. NASCIMENTO APS, et al. Implicações das concentrações séricas de selênio nas doenças inflamatórias intestinais: uma revisão bibliográfica. Revista Eletrônica Acervo Saúde, 2020;12(2): e2101.

10. PILEGGI GS, et al. Recomendações brasileiras sobre a segurança e eficácia da vacinação contra a febre amarela em pacientes com doenças inflamatórias crônicas imunomediadas. Avanços em Reumatologia, 2019;59:17.

11. PROTASIO BKPF, et al. Especificidades da apresentação da doença de Chron na infância. Einstein (São Paulo), 2018; 16(1): eRC4070.

12. SILVA FARS, et al. A análise transcricional completa identifica marcadores de $B, T$ e vias de sinalização de células plasmáticas no tecido adiposo mesentérico associado à doença de Chron. Journal of Translational Medicine, 2020; 44(18).

13. SILVA MT, et al. Diagnóstico e tratamento da síndrome do intestino irritável: revisão sistemática. Pará Research Medical Journal, 2020:e41.

14. SOUZA FG, et al. Adesão ao tratamento farmacológico em pacientes com doenças inflamatórias intestinais: uma revisão integrativa da literatura. Revista Eletrônica Acervo Saúde, 2021;13(2), e4601.

15. SU HJ, et al. Doença inflamatória intestinal e seu tratamento em 2018: atualizações de status globais e de Taiwan. Journal of the Formosan Medical Association, 2019;118(7):1083-1092.

16. TORRES J, et al. Crohns disease. Lancet, 2017; 389(10080): 1741-55.

17. ZALTMAN C, et al. Doença de Chron- tratamento com medicamentos biológicos. Revista da Associação Médica Brasileira Online, 2019;65(4): 554-567. 